\title{
AN ASSESSMENT OF BEAM-TO-COLUMN ENDPLATE AND BASEPLATE JOINTS INCLUDING THE AXIAL-MOMENT INTERACTION
}

\author{
A.A. Del Savio ${ }^{1, *}$, D.A. Nethercot ${ }^{2}$, P.C.G.S. Vellasco ${ }^{3}$, L.R.O. de Lima ${ }^{3}$, \\ S.A.L. Andrade ${ }^{4}$ and L.F. Martha ${ }^{4}$ \\ ${ }^{I}$ Civil Engineering Department, PUC-Rio - Pontifical Catholic University of Rio de Janeiro \& \\ Department of Civil and Environmental Engineering, Imperial College London \\ Rua Marquês de São Vicente, 225, Gávea, Rio de Janeiro, RJ-Brazil, CEP: 22453-900 \\ ${ }^{2}$ Department of Civil and Environmental Engineering, Imperial College London \\ South Kensington Campus, Skempton Building, London SW7 2BU, United Kingdom \\ ${ }^{3}$ Structural Engineering Department, UERJ - State University of Rio de Janeiro \\ Rua São Francisco Xavier, 524, Sala 5018A, Maracanã, Rio, RJ, Brazil, CEP: 20550-900 \\ ${ }^{4}$ Civil Engineering Department, PUC-Rio - Pontifical Catholic University of Rio de Janeiro \\ Rua Marquês de São Vicente, 225, Gávea, Rio de Janeiro, RJ-Brazil, CEP: 22453-900 \\ *(Corresponding author: E-mail: a.delsavio@imperial.ac.uk/delsavio@gmail.com)
}

Received: 26 June 2007; Revised: 30 November 2008; Accepted: 3 December 2008

\begin{abstract}
Knowledge of the moment-rotation characteristic of connections is an essential prerequisite for use of the so called semi-continuous approach to steel and composite frame design. Although the axial force transferred from the beam is frequently low, so that its effect on the moment-rotation characteristic may often be neglect, certain circumstances do exist in which axial compression or tension forces will be sufficiently large that it is no longer reasonable to ignore their influence. Relatively few experimental results have been reported to investigate this effect. A method is presented herein which extends the range of application of available data so as to produce moment-rotation characteristics that implicitly make proper allowance for the presence of significant levels of either tension of compression in the beam. The method depends directly on the availability of a limited amount of data but then uses a corrective process to permit the full range to be covered. The applicably and validity of the proposed methodology is demonstrated through comparisons against several tests on both flush end-plate joints and base plate arrangements.
\end{abstract}

Keywords: Axial versus bending moment interaction; joint behaviour; moment versus rotation curves; rotational stiffness, semi-rigid joints; steel structures

\section{INTRODUCTION}

Under certain circumstances, beam-to-column joints can be subjected to the simultaneous action of bending moments and axial forces. Although, the axial force transferred from the beam is usually low, it may, in some situations attain values that significantly reduce the joint flexural capacity. These conditions may be found in: Vierendeel girder systems (widely used in building construction because they take advantage of the member flexural and compression resistances eliminating the need for extra diagonal members); regular sway frames under significant horizontal loading (seismic or extreme wind); irregular frames (especially with incomplete storeys) under gravity/horizontal loading; and pitched-roof frames.

Moreover, with the recent escalation of terrorist attacks on buildings, the study of progressive collapse of steel framed building has been highlighted, as can be seen in Vlassis et al. [16]. Examples of these exceptional conditions are the cases where structural elements, such as central and/or peripheral columns and/or main beams, are suddenly removed, sharply increasing the joint axial forces. In these situations the structural system, mainly the joints, should be sufficiently robust to prevent the premature failure modes that may lead to progressive structural collapse.

Unfortunately, few experiments considering the interaction bending moment and axial force have been reported in the literature. Additionally, the available experiments are associated with a small 
number of axial force levels and associated bending moment versus rotation curves, $M-\phi$. Thus the, a question still remains for how to incorporate these effects into a structural analysis. There is, therefore, the need of $M-\phi$ curves associated with varying axial force levels, which accurately represent the joint resistance rotational stiffness.

This has led to the development of a relatively simple yet accurate approach to predict any moment versus rotation curve from tests that include the axial versus bending moment interaction. The evaluation and validation of this methodology is executed against a range of available experimental tests for flush endplate joints (Simões da Silva et al., [13]) and base plate joints (Guisse et al. [4]). It is worth highlighting that this methodology is not only restricted to the use of experiments, but can also be applied to results obtained analytically, empirically, mechanically and numerically.

Since this methodology is exclusively based on the use of $M$ - $\phi$ curves, the bending moment versus axial force interactions are intrinsically incorporated, it can be easily implemented into a nonlinear semi-rigid joint finite element formulation because it does not change the element formulation, only requiring a rotational stiffness update procedure.

\subsection{Component Method}

The component method entails the use of relatively simple joint mechanical models, based on a set of rigid links and spring components. The component method - introduced in Eurocode 3 [3] - can be used to determine the joint's resistance and initial stiffness. Its application requires the identification of active components, the evaluation of the force-deformation response of each component (which depends on mechanical and geometrical properties of the joint) and the subsequent assembly of the active components for the evaluation of the joint moment versus rotation response.

Nowadays, using the Eurocode 3 [3] component method, it is possible to evaluate the rotational stiffness and moment capacity of semi-rigid joints when subject to pure bending. However, this component method is not yet able to calculate these properties when, in addition to the applied moment, an axial force is also present. Eurocode 3 [3] suggests that the axial load may be disregarded in the analysis when its value is less than 5\% of the beam's axial plastic resistance, but provides no information for cases involving larger axial forces. Although, the component method does not consider the presence of an axial force, its general principles could be used in these situations. The main reason for this is related to the fact that the Eurocode 3 [3] is based on the use of a series of force versus displacement relationships - which only depend on the component's axial force level - to characterize any individual component behaviour.

\subsection{Background: Experimental and Theoretical Models}

The study of the semi-rigid characteristics of beam-to-column joints and their effects on frame behaviour can be traced back to the 1930s, Li et al. [6]. Since then, a large amount of experimental and theoretical work has been conducted both on the behaviour of the joints and on their effects on complete frame performance. 
Despite the large number of available experiments, they do not cover the full range of interest. As an alternative to tests, other methods have been proposed to predict bending moment versus rotation curves. These procedures range from a purely empirical curve fitting of test data, passing through ingenious behavioural, analogy and semi-empirical techniques, to comprehensive finite element analysis, Nethercot \& Zandonini [10].

Recently, several researchers have paid special attention to joint behaviour under combined bending moment and axial force. Guisse et al. [4] carried out experiments on twelve column bases, six with extended and six with flush endplates. Wald and Svarc [17] tested three flush endplate beam-to-beam joints and two extended endplate beam-to-column joints; however there is no reference to tests made without axial forces, which is necessary as a basis to study the influence of axial force on the joint structural response. Lima et al. [8] and Simões da Silva et al. [13] performed tests on eight flush and seven extended endplate joints. The investigators concluded that the presence of the axial force modifies their structural response and, therefore, should be considered in the joint structural design.

Regarding the theoretical models, Table 1 summarises the mechanical models that have been developed since 1993 to predict the behaviour of beam-to-column joints under bending moment and axial force.

Table 1. Summary of Mechanical Models Used to Predict the Joint Behaviour Subjected to Bending Moments and Axial Forces

\begin{tabular}{ll}
\hline Authors (date) & Type of Joint \\
\hline Wales \& Rossow [18] & Double web cleat connections \\
Madas [9] & $\begin{array}{l}\text { Flexible endplate, double web angle and } \\
\text { top and seat angle connections }\end{array}$ \\
Jaspart et al. [5] and Cerfontaine [1] & Extended and flush endplate connections \\
Simões da Silva \& Coelho [12] & Welded beam-to-column joints \\
Sokol et al. [14] & Endplate joints \\
Lima [7] and Lima et al. [8] & Extended endplate joints \\
Lima [7] and Simões da Siva et al. [13] & Flush endplate joints \\
& Flush and extended endplate, top-and-seat \\
Ramli-Sulong [11] & and/or web angles, and fin-plate \\
& connections \\
Urbonas \& Daniunas [15] & Endplate bolted beam-to-beam joints \\
\hline
\end{tabular}

Despite the continuous development and improvement of these analytical models there are still limitations in the prediction of the moment-rotation curves, mainly related to the joint initial stiffness for different axial force levels. Usually, the severity of this problem increases when joints are subjected to tensile axial forces and it is commonly related to the ability of these models to deal with moment-axial interaction, consequently changing the compressive centre, before the first component yields.

With the aim of providing an alternative method to the mechanical models for prediction of moment-rotation curves for any axial force level from a limited set of experiments, the next section presents a detailed methodology based on the use of Correction Factors initially proposed by Del Savio et al. [2]. 


\section{PREDICTION OF MOMENT-ROTATION CURVES FOR ANY AXIAL FORCE LEVEL FROM A LIMITED SET OF EXPERIMENTS}

\subsection{General Concepts of the Correction Factor}

The Correction Factor was initially proposed by Del Savio et al. [2] to allow for the bending moment versus axial force interaction, by scaling original moment values present in the moment versus rotation curves (disregarding the axial force effect). This strategy shifts this curve up or down depending on the axial force level. However, as it only modifies the bending moment axis, it is not able to fully describe the bending moment versus rotation associated with different axial force levels. This fact is highlighted when the joint is subject to a tensile axial force, where there is a significant difference, mainly, in terms of initial stiffness.

With the aim of improving this basic idea, the Correction Factor has been divided into two parts: one for the moment axis and another for the rotation axis. Both corrections are in principle independent, and do not depend on the moment versus axial force interaction diagram, as was the case for the initial idea presented by Del Savio et al. [2]. It is now only a function of the moment versus rotation curves for different axial force levels.

\subsection{Extension of the Correction Factors for Both Bending Moment and Rotation Axes}

As previously noted, there are two corrections, one to the moment axis and another to the rotation axis. As a general approach, the Correction Factor for the moment axis is evaluated in terms of the bending moment versus rotation curves considering the axial force effect. Using the design bending moment ratio and considering the axial force effect, the Correction Factor for the moment axis, $C F_{M}$, can be evaluated by:

$$
C F_{M}=\frac{M_{\text {int }}}{M_{\text {max }}} \quad \begin{aligned}
& M_{\text {int }}=f\left(M x \phi\left(N_{i}\right)\right) \\
& M_{\text {max }}=f(M x \phi(0.0))
\end{aligned}
$$

where $N_{i}$ is the axial force present in the $i$ interaction; $M x \phi$ or $M-\phi$ is the bending moment versus rotation curve; $M_{\text {int }}$ is the design bending moment for the $M-\phi\left(N_{i}\right)$ curve considering the axial force $N_{i}$; and $M_{\max }$ is the design bending moment for the $M-\phi(0.0)$ curve without axial forces. $M_{\text {int }}$ and $M_{\max }$ can be determined according to Eurocode 3 [3], through the intersection between two straight lines, one parallel to the initial stiffness and another parallel to the $M$ - $\phi$ curve post-limit stiffness, Figure 1.

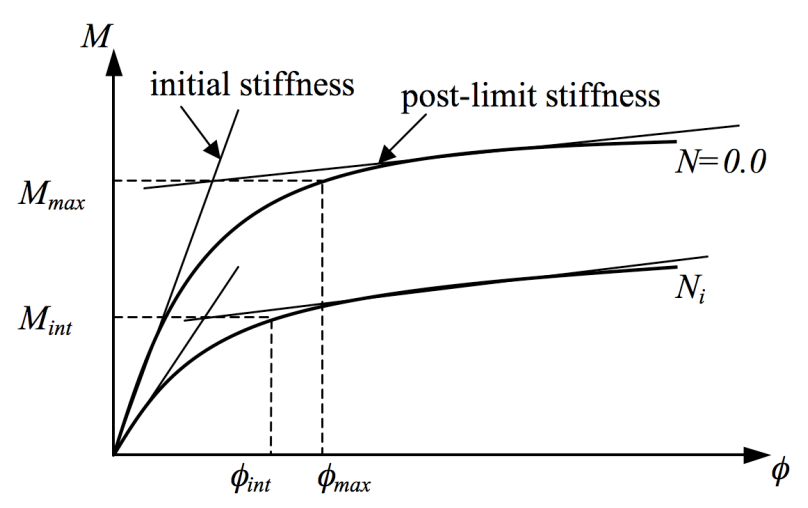

Figure 1. Evaluation of the Design Bending Moments $\left(M_{\text {int }} \& M_{\max }\right)$ and Rotations $\left(\phi_{i n t} \& \phi_{\max }\right)$ 
Similarly, the rotation axis Correction Factor, $C F_{\phi}$ is evaluated using the design rotation ratio, i.e.:

$$
C F_{\phi}=\frac{\phi_{\text {int }}}{\phi_{\text {max }}} \quad \begin{aligned}
& \phi_{\text {int }}=f\left(M x \phi\left(N_{i}\right)\right) \\
& \phi_{\text {max }}=f(M x \phi(0.0))
\end{aligned}
$$

where $\phi_{i n t}$ and $\phi_{\max }$ are the design rotations related respectively to $M_{\text {int }}$ and $M_{\max }$. Both design rotations are found by tracing a horizontal straight line at the design moment level until it reaches the $M-\phi$ curve. At this point a vertical straight line is drawn until it intersects the rotation axis, Figure 1. With the Correction Factors evaluated for both the moment and rotation axes, Eqs. 1 and 2 respectively, they are then incorporated into the joint structural response considering the moment versus axial force interaction by modifying the $M-\phi$ curve for the zero axial force case, i.e.:

$$
\begin{aligned}
& \operatorname{Mx} \phi(0.0) \rightarrow \operatorname{Mx} \phi\left(N_{i}\right) \\
& \operatorname{Mx} \phi\left(N_{i}\right)=\operatorname{Mx} \phi\left(M_{N=0} \times C F_{M}, \phi_{N=0} \times C F_{\phi}\right)
\end{aligned}
$$

Basically, the $M-\phi$ curve point coordinates $M_{N=0}$ and $\phi_{N=0}$ referred to the moment and the rotation axis coordinates, respectively, for the case without axial forces, are multiplied by the Correction Factors $C F_{M}$ and $C F_{\phi}$, respectively.

However, only using a pair of Correction Factors throughout the whole $M-\phi$ curve, for the case without axial forces, does not provide a good approximation to the $M-\phi$ curve considering the axial force, because its response is very sensitive to the adopted initial and post-limit stiffnesses.

This prompted the division of the $M-\phi$ curve into three segments with different pairs of Correction Factors. These divisions were made at two-third, one, and 1.1 times the design bending moment $M_{d}$ as shown in Figure 2.

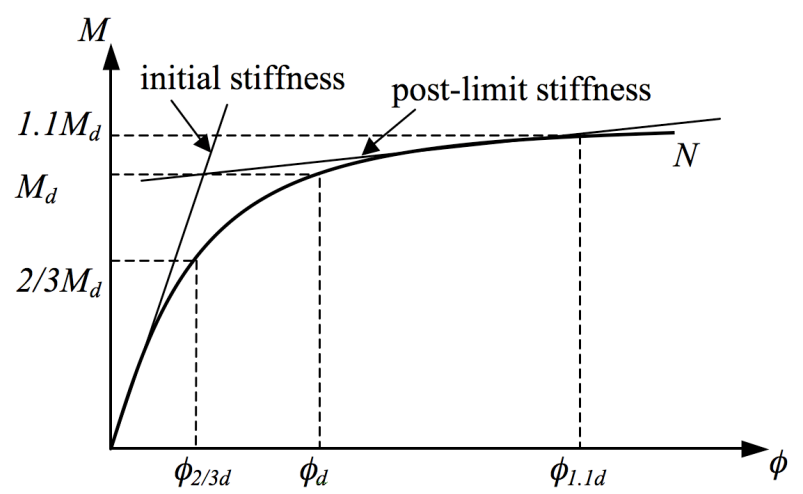

Figure 2. Correction Factor strategy method using a three segment division of the $M-\phi$ curve

With this division, the Correction Factors cannot be applied as presented in Eq. 3. This is justified, in fact, because they would provoke two abrupt variations of stiffness throughout the approximate $M-\phi$ curve at around the point of intersection of the approximate curve with the vertical lines at the points $\phi_{2 / 3 d}$ and $\phi_{d}$, Figure 3. This is due to the use of three different pairs of Correction Factors evaluated according to Eqs. 1 and 2 at two-third, one, and 1.1 times the design bending moment $M_{d}$. 


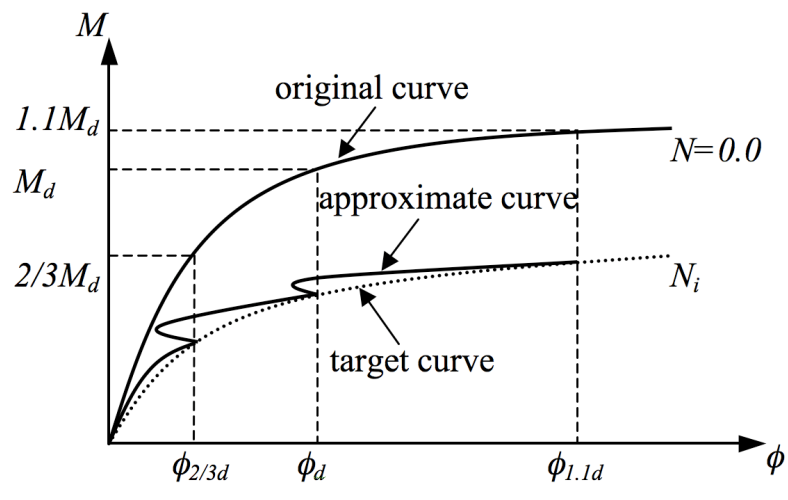

Figure 3. Approximate $M-\phi$ curve using three Correction Factor pairs

\subsection{An Alternative Methodology}

Based on the division of the $M-\phi$ curve into three segments with different pairs of Correction Factors, previously mentioned, in Figure 4, a tri-linear representation for the $M$ - $\phi$ curve was proposed. This method overcomes the problem of abrupt alterations of stiffness presented in Figure 3 as well as guaranteeing an accurate approximation of the $M-\phi$ curve at points: $\left(2 / 3 M_{d}, \phi_{2 / 3 d}\right) ;\left(M_{d}\right.$, $\left.\phi_{d}\right)$ and $\left(1.1 M_{d}, \phi_{1.1 d}\right)$.

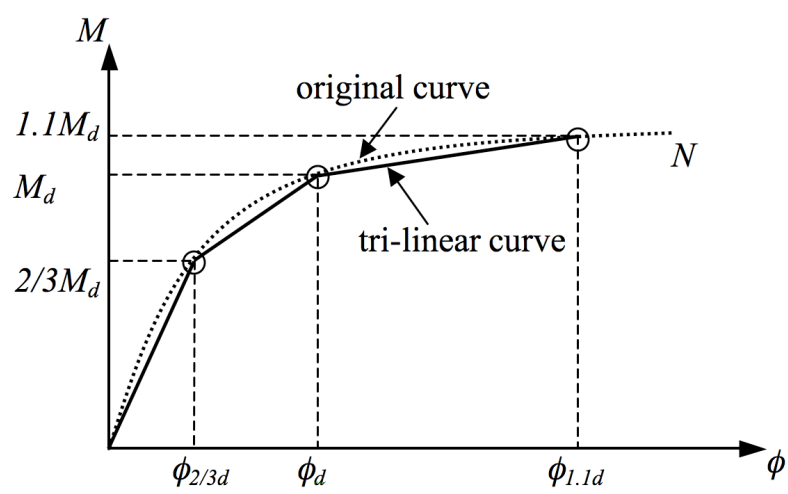

Figure 4. Tri-linear representation of the $M-\phi$ curve methodology

From the tri-linear representation proposed in Figure 4, the bending moments of the target $M-\phi$ curve, associated with a certain axial force level $\left(N_{i}\right)$, can be evaluated by:

$$
\begin{aligned}
& M_{p}=\left(M_{N, p}-M_{0, p}\right) \frac{N_{i}}{N}+M_{0, p} \\
& p=2 / 3 M_{d} ; M_{d} ; 1.1 M_{d} \\
& 0<N_{i} \leq N \rightarrow \text { tensile axial force } \\
& N \leq N_{i}<0 \rightarrow \text { compressive axial force }
\end{aligned}
$$

where the subscript $p$ refers to three analysed points: $2 / 3 M_{d}, M_{d}$, and $1.1 M_{d} ; N$ is the axial force load level associated with the reference $M-\phi$ curve; $N_{i}$ is the axial force load level related to the target $M$ - $\phi$ curve; $M_{p}$ is the bending moment evaluated for the target $M-\phi$ curve at point $p ; M_{N, p}$ is the bending moment on the reference $M-\phi$ curve considering the axial force at point $p$; and $M_{0, p}$ is the bending moment on the reference $M$ - $\phi$ curve without axial forces at point $p$. 
Likewise, the rotations of the evaluated $M-\phi$ curve, for the associated $N_{i}$, can be calculated by:

$$
\begin{aligned}
& \phi_{p}=\left(\phi_{N, p}-\phi_{0, p}\right) \frac{N_{i}}{N}+\phi_{0, p} \\
& p=2 / 3 M_{d} ; M_{d} ; 1.1 M_{d} \\
& 0<N_{i} \leq N \rightarrow \text { tensile axial force } \\
& N \leq N_{i}<0 \rightarrow \text { compressive axial force }
\end{aligned}
$$

where $\phi_{p}$ is the rotation evaluated for the target $M-\phi$ curve at point $p ; \phi_{N, p}$ is the rotation on the reference $M-\phi$ curve considering the axial force at point $p$; and $\phi_{0, p}$ is the rotation on the reference $M-\phi$ curve without axial force effects at point $p$.

The evaluations of the bending moments and rotations proposed in Eqs. 4 and 5, respectively, for prediction of the target $M-\phi$ curve are, in essence, linear interpolations between two reference $M-\phi$ curves - considering and disregarding the axial force - at points: $\left(2 / 3 M_{d}, \phi_{2 / 3 d}\right) ;\left(M_{d}, \phi_{d}\right)$ and $\left(1.1 M_{d}\right.$, $\left.\phi_{1.1 d}\right)$.

\section{APPLICATION OF THE PROPOSED METHODOLOGY}

The main focus of the methodology presented in section 2.3 is to determine $M-\phi$ curves for any axial force level from two reference $M-\phi$ curves. The quality of the obtained approximations depends on the quality of the $M-\phi$ curves used as input to the method. This methodology requires, at least, two $M-\phi$ curves, disregarding and considering either the compressive or tensile axial force effect. However, for a complete behavioural evaluation of the joint three $M-\phi$ curves are necessary: one disregarding the axial force effect; another considering the compressive force effect and finally a third alternative considering the tensile force effect. In this way, it is possible to study the entirely joint structural response given that loading applied to the joint may vary from compression to tension.

In order to explain the application of this method to obtain $M-\phi$ curves for any axial force level, as well as to validate its use, experimental tests carried out by Simões da Silva et al. [13] and Guisse et al. [4] on eight flush endplate joints and twelve column bases have been used.

\subsection{Flush Endplate Joints}

This section evaluates experimental tests carried out by Simões da Silva et al. [13] on eight flush endplate joints. The geometric properties of the flush endplate, the $M-\phi$ curves describing the experimental behaviour of each test, and the bending moment versus axial force interaction diagram are shown in Figures 5 to 7. 


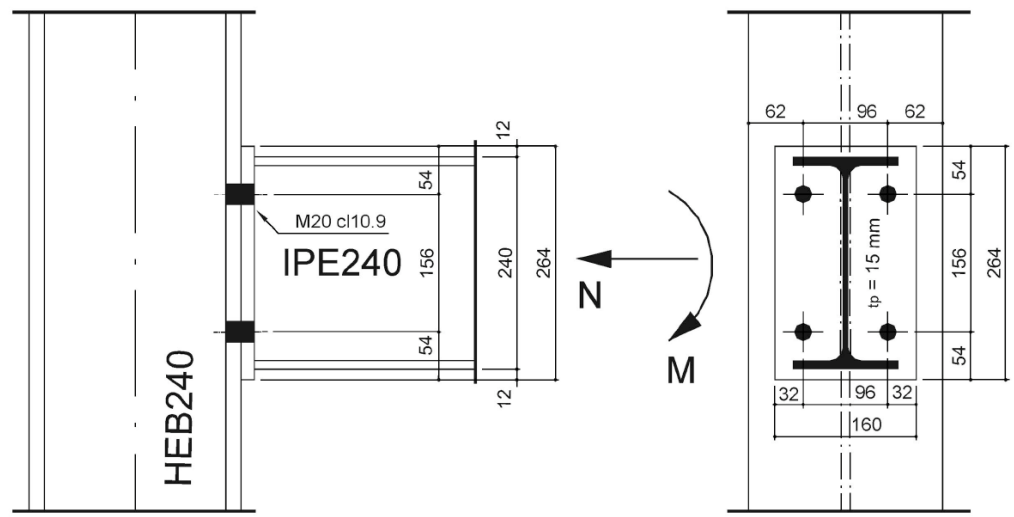

Figure 5. Flush endplate joint layout, Simões da Silva et al. [13]

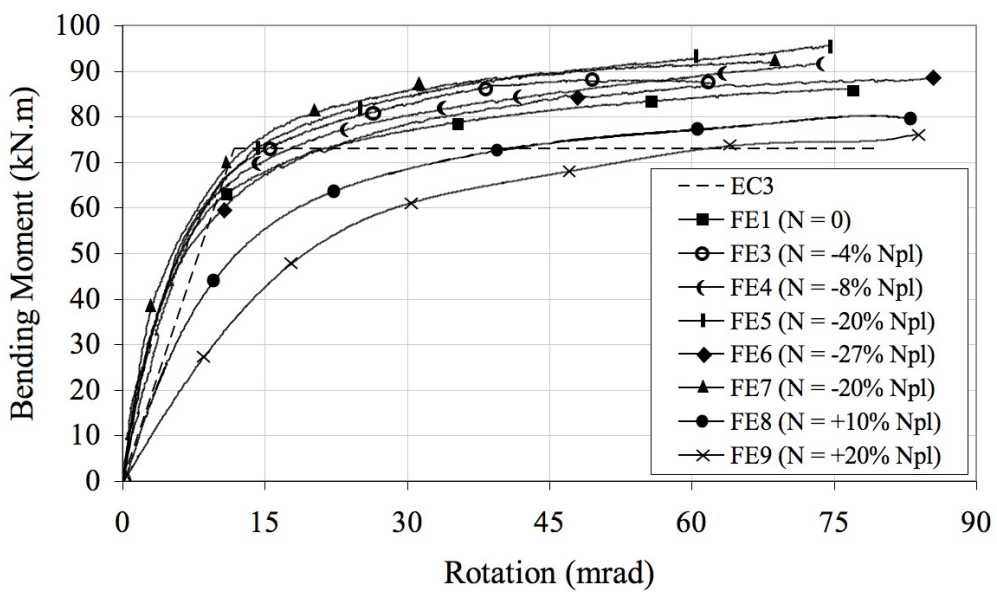

Figure 6. Experimental moment versus rotation curves, Simões da Silva et al. [13]

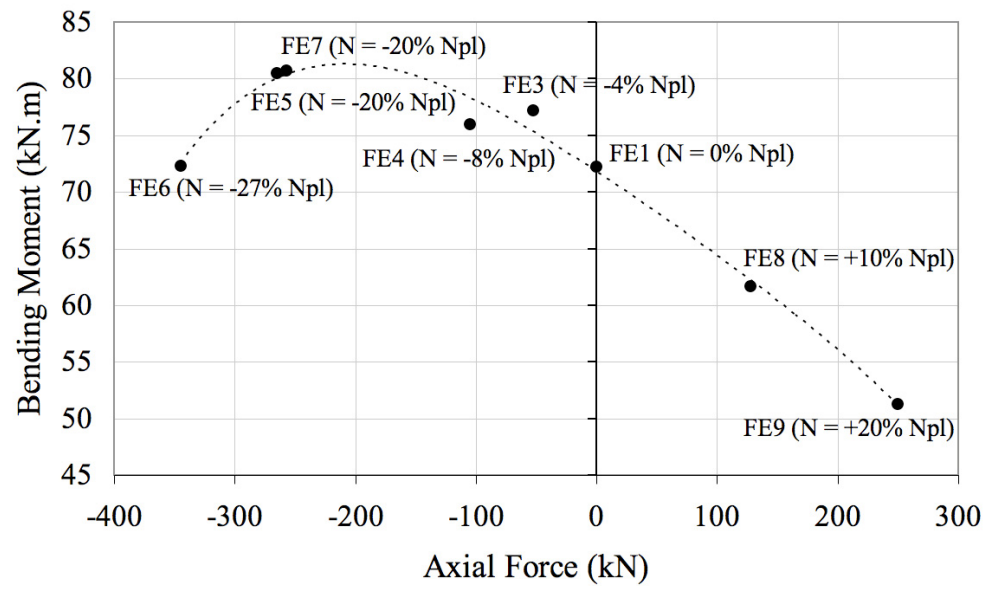

Figure 7. Flush endplate bending moment versus axial force interaction diagram, Simões da Silva et al. [13]

The experimental data, Figure 6, provides the necessary input for the proposed method. The minimum input is composed of two $M-\phi$ curves, disregarding and considering either the tensile or compressive axial force. However, the flush endplate joint, tested by Simões da Silva et al. [2], exhibited a decrease in the moment resistance for the tensile axial forces whilst achieving the highest moment resistance for a compressive axial force equal to $20 \%$ of the beam's axial plastic resistance (see Figure 7, FE7). Three reference $M-\phi$ curves were adopted to demonstrate this joint's 
behaviour relative to the type of axial force: FE1 $(N=0)$; FE7 $(N=-257 \mathrm{kN},-20 \% \mathrm{Npl}$, compressive force), and FE9 $(N=250 \mathrm{kN},+20 \% \mathrm{Npl}$, tensile force), where $\mathrm{Npl}$ is the beam's axial plastic resistance. These three experimental curves and their tri-linear approximations are shown in Figure 8. Additionally, Table 2 presents all the values evaluated for these tri-linear approximations according to Figure 2, where the points for each tri-linear reference $M-\phi$ curve were obtained from the joint design moment, $M_{d}$, which is given by the intersection between two straight lines, one parallel to the initial stiffness and another parallel to the $M-\phi$ curve post-limit stiffness.

Table 2. Values Evaluated for the Reference $M-\phi$ Curves

\begin{tabular}{|c|c|c|c|c|c|c|}
\hline \multirow[b]{2}{*}{ Point } & \multicolumn{2}{|c|}{$\begin{array}{c}F E 1 \\
(N=0.0)\end{array}$} & \multicolumn{2}{|c|}{$\begin{array}{c}F E 7 \\
(N=-257 \mathrm{kN},-20 \% \\
N p l)\end{array}$} & \multicolumn{2}{|c|}{$\begin{array}{c}F E 9 \\
(N=+250 \mathrm{kN},+20 \% \\
N p l)\end{array}$} \\
\hline & $\phi(m r a d)$ & $M(k N m)$ & $\phi(\mathrm{mrad})$ & $M(k N m)$ & $\phi(m r a d)$ & $M(k N m)$ \\
\hline 0 & 0.0 & 0.0 & 0.0 & 0.0 & 0.0 & 0.0 \\
\hline $2 / 3 M_{d}$ & 6.3 & 50.6 & 6.8 & 56.1 & 13.0 & 38.4 \\
\hline$M_{d}$ & 27.6 & 76.0 & 26.8 & 84.1 & 25.8 & 57.7 \\
\hline $1.1 M_{d}$ & 56.1 & 83.5 & 67.3 & 92.2 & 35.0 & 63.5 \\
\hline
\end{tabular}

Tri-linear $M$ - $\phi$ curves, Figure 8 , are used to define paths between each curve at points $2 / 3 M_{d}, M_{d}$ and $1.1 M_{d}$, Figure 9. These paths were used to guide the linear interpolators for bending moments, Eq. 4, and rotations, Eq. 5, throughout the given range of axial force levels to determine the required set of $M-\phi$ curves.

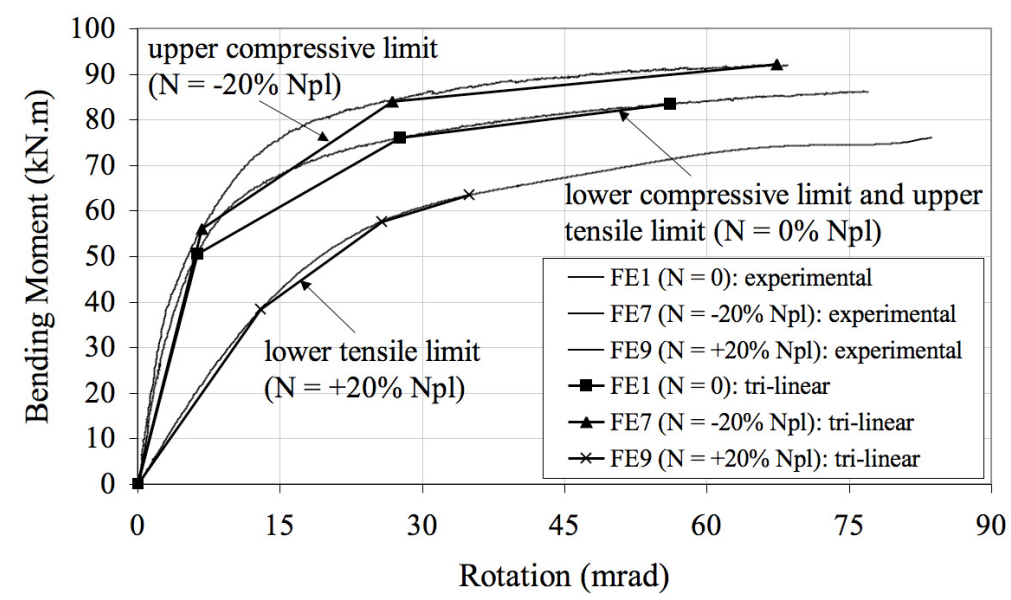

Figure 8. Tri-linear Strategy Used for the Experimental $M-\phi$ Curves

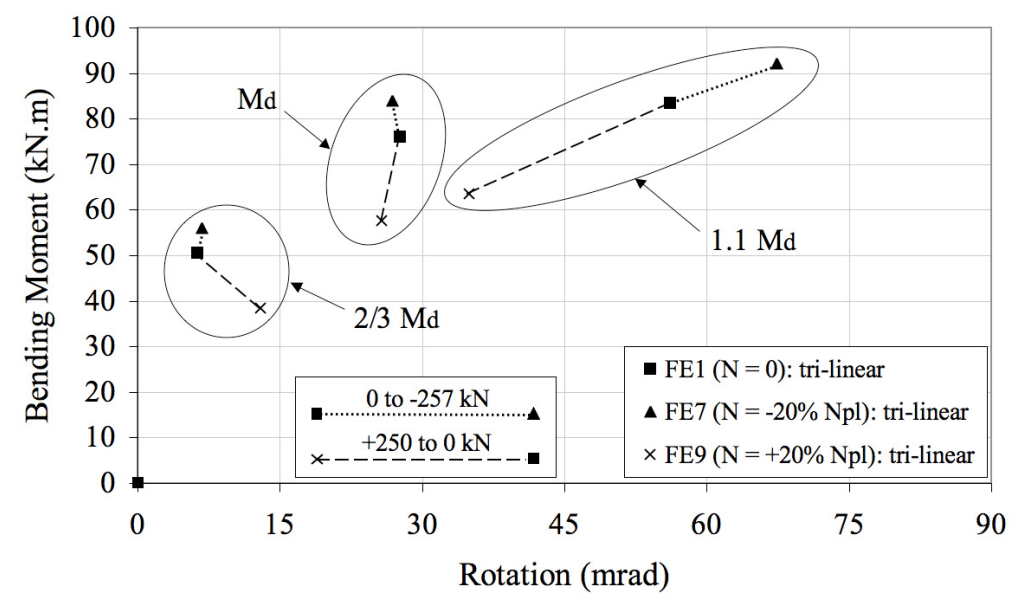

Figure 9. Paths Used to Define the Procedure to

Determine any $M-\phi$ Curve Present within these Limits 
Subsequently, Table 3 depicts the results obtained by using the proposed methodology to predict three experimental $M-\phi$ curves: FE8 for a $10 \%$ tensile force of the beam's axial plastic resistance, FE3 and FE4 for compressive forces of $4 \%$ and $8 \%$, respectively, of the beam's axial plastic resistance. Following this strategy, as an example, Eq. 6 demonstrates how to calculate point $1.1 M_{d}$, Table 3, of the FE8 approximated $M-\phi$ curve. Figures 10 to 12 graphically depict these results. Figure 13 presents the whole set of predicted $M-\phi$ curves utilising this methodology.

Table 3. Values evaluated for three tri-linearly approximated $M-\phi$ curves

\begin{tabular}{|c|c|c|c|c|c|c|}
\hline \multirow[b]{2}{*}{ Point } & \multicolumn{2}{|c|}{$\begin{array}{c}F E 3 \\
\left(N_{i}=-53 k N,-4 \%\right. \\
N p l)\end{array}$} & \multicolumn{2}{|c|}{$\begin{array}{c}F E 4 \\
\left(N_{i}=-105 k N,-8 \% ~ N p l\right)\end{array}$} & \multicolumn{2}{|c|}{$\begin{array}{c}F E 8 \\
\left(N_{i}=+128 k N,+10 \%\right. \\
N p l)\end{array}$} \\
\hline & $\phi(m r a d)$ & $M(k N m)$ & $\phi(m r a d)$ & $M(k N m)$ & $\phi(\mathrm{mrad})$ & $M(k N m)$ \\
\hline 0 & 0.0 & 0.0 & 0.0 & 0.0 & 0.0 & 0.0 \\
\hline $2 / 3 M_{d}$ & 6.4 & 51.8 & 6.5 & 52.9 & 9.7 & 44.4 \\
\hline$M_{d}$ & 27.4 & 77.6 & 27.3 & 79.3 & 26.7 & 66.6 \\
\hline $1.1 M_{d}$ & 58.4 & 85.3 & 60.7 & 87.1 & 45.3 & 73.3 \\
\hline
\end{tabular}

FE8 : $\quad$ Point $=p=1.1 M_{d}$

$M_{p}=\left(M_{N, p}-M_{0, p}\right) \frac{N_{i}}{N}+M_{0, p}=(63.5-83.5) \frac{128.0}{250.0}+83.5=73.3 \mathrm{kNm}$

$\phi_{p}=\left(\phi_{N, p}-\phi_{0, p}\right) \frac{N_{i}}{N}+\phi_{0, p}=(35.0-56.1) \frac{128.0}{250.0}+56.1=45.3 \mathrm{mrad}$

$M_{N, p} ; \phi_{N, p}$ and $N \rightarrow$ Table $2: F E 9$

$M_{0, p}$ and $\phi_{0, p} \quad \rightarrow$ Table $2: F E 1$

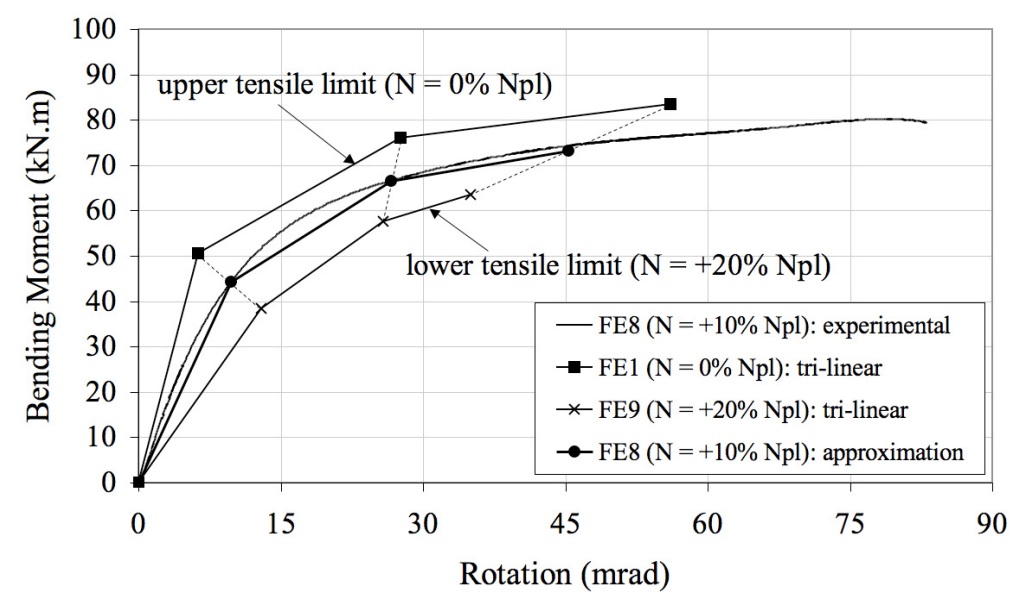

Figure 10. FE8 $M$ - $\phi$ Curve Approximation, Considering a Tensile Force of 10\% of the Beam's Axial Plastic Resistance 


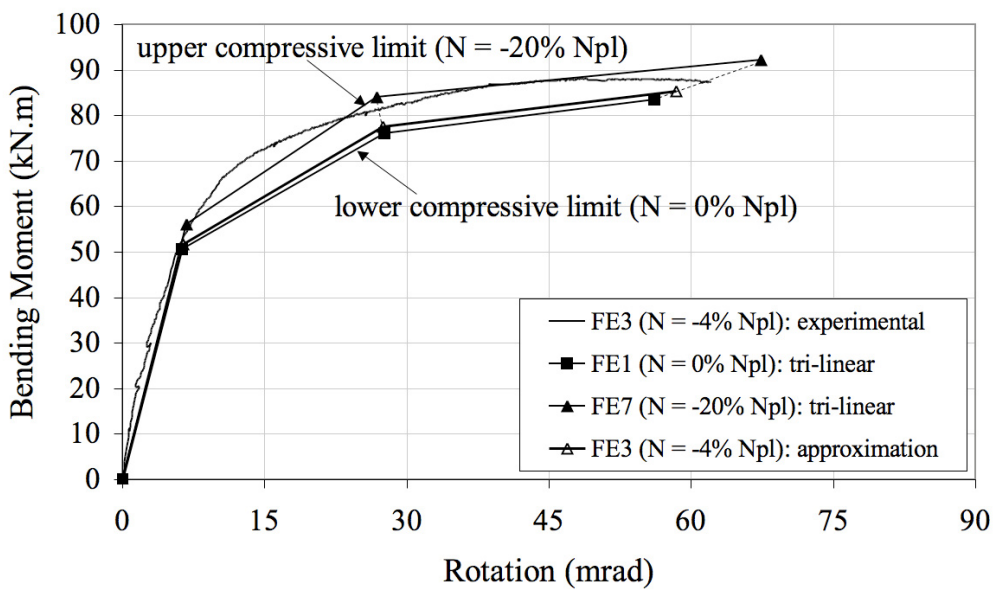

Figure 11. FE3 $M-\phi$ Curve Approximation, Considering a Compressive Force of $4 \%$ of the Beam's Axial Plastic Resistance

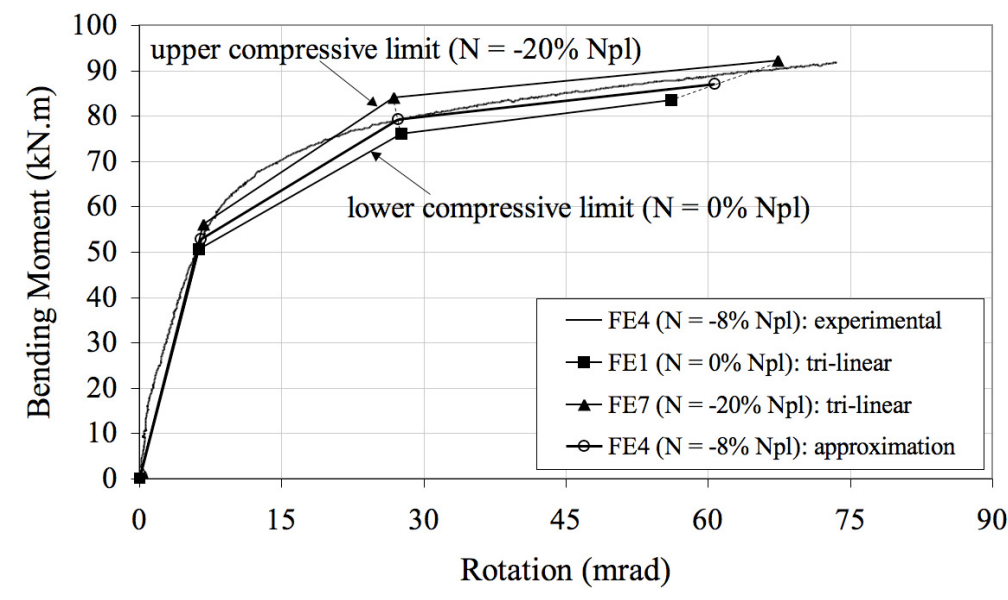

Figure 12. FE4 $M-\phi$ Curve Approximation, Considering a Compressive Force of $8 \%$ of the Beam's Axial Plastic Resistance

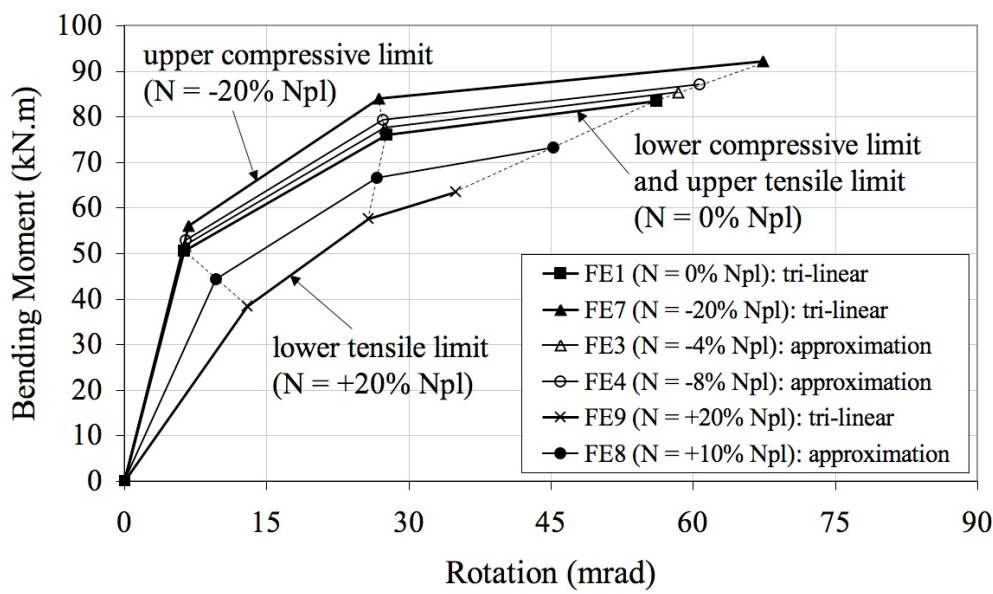

Figure 13. The Whole Set of Predicted $M$ - $\phi$ Curves by Using the Proposed Methodology 


\subsection{Column Bases}

This section presents the evaluation of the experiments performed by Guisse et al. [4] on twelve column base joints. Test configurations with respectively four and two anchor bolts, Figures 14(a) and 14(b), were considered. The steel column profile was a S355 HE160B, whilst the S235 base plates utilised two different thicknesses: $15 \mathrm{~mm}$ and $30 \mathrm{~mm}$. The baseplates are welded to the column with 6 mm fillet welds connected with M20 10-9 anchor bolts.

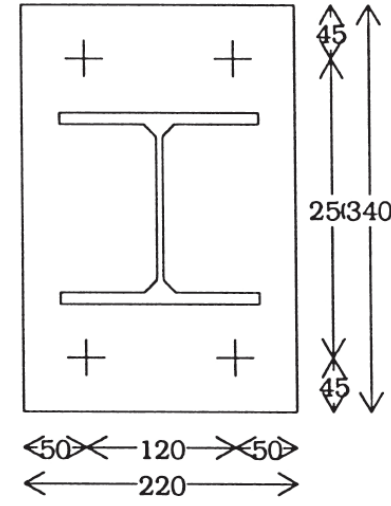

(a) Four anchor bolts

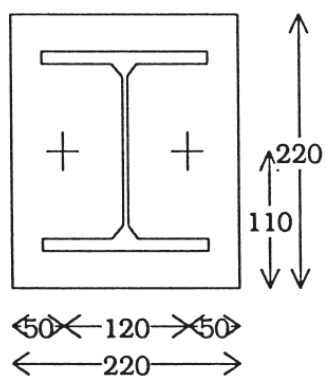

(b) Two anchor bolts

Figure 14. Baseplate Configurations, Guisse et al. [4]

Table 4 presents the set of the tested column bases and Figures 15 to 18 show the experimental $M-\phi$ curves obtained by Guisse et al. [4].

Table 4. Nomenclature of the Tests and their Parameters, Guisse et al. [4]

\begin{tabular}{lccc}
\hline \multicolumn{1}{c}{ Name } & Anchor bolts & Plate thickness $(\mathbf{m m})$ & Normal force $(\mathbf{k N})$ \\
\hline$P C 2.15 .100$ & 2 & 15 & 100 \\
$P C 2.15 .600$ & 2 & 15 & 600 \\
$P C 2.15 .1000$ & 2 & 15 & 1000 \\
$P C 2.30 .100$ & 2 & 30 & 100 \\
$P C 2.30 .600$ & 2 & 30 & 600 \\
$P C 2.30 .1000$ & 2 & 30 & 1000 \\
$P C 4.15 .100$ & 4 & 15 & 100 \\
$P C 4.15 .400$ & 4 & 15 & 400 \\
$P C 4.15 .1000$ & 4 & 15 & 1000 \\
$P C 4.30 .100$ & 4 & 30 & 100 \\
$P C 4.30 .400$ & 4 & 30 & 400 \\
$P C 4.30 .1000$ & 4 & 30 & 1000 \\
\hline
\end{tabular}

Since the experiments used only compressive forces, two reference $M-\phi$ curves were adopted for each set of tests related to the axial forces of 100 and $1000 \mathrm{kN}$. The experimental $M-\phi$ curves and their tri-linear approximations are shown in Figures 15 to 18. Additionally, Table 5 presents all the values evaluated for these tri-linear approximations according to Figure 2. 
Table 5. Values Evaluated for the Reference $M-\phi$ Curves

\begin{tabular}{|c|c|c|c|c|c|c|c|c|c|c|c|c|c|c|c|c|}
\hline \multirow{3}{*}{$\frac{5}{2}$} & \multicolumn{8}{|c|}{$P C 2$} & \multicolumn{8}{|c|}{$P C 4$} \\
\hline & \multicolumn{2}{|c|}{15.100} & \multicolumn{2}{|c|}{15.1000} & \multicolumn{2}{|c|}{30.100} & \multicolumn{2}{|c|}{30.1000} & \multicolumn{2}{|c|}{15.100} & \multicolumn{2}{|c|}{15.1000} & \multicolumn{2}{|c|}{30.100} & \multicolumn{2}{|c|}{30.1000} \\
\hline & $\phi$ & $M$ & $\phi$ & $\boldsymbol{M}$ & $\phi$ & $M$ & $\phi$ & $M$ & $\phi$ & $M$ & $\phi$ & $M$ & $\phi$ & $M$ & $\phi$ & $M$ \\
\hline 0 & 0.0 & 0.0 & 0.0 & 0.0 & 0.0 & 0.0 & 0.0 & 0.0 & 0.0 & 0.0 & 0.0 & 0.0 & 0.0 & 0.0 & 0.0 & 0.0 \\
\hline $2 / 3 M_{d}$ & 21.0 & 21.3 & 9.0 & 41.3 & 25.0 & 17.3 & 10.5 & 46.0 & 10.0 & 32.0 & 16.0 & 62.7 & 12.0 & 46.0 & 11.07 & 72.0 \\
\hline$M_{d}$ & 40.0 & 32.0 & 30.0 & 62.0 & 44.0 & 26.0 & 29.0 & 69.0 & 28.0 & 48.0 & 40.0 & 94.0 & 33.0 & 69.0 & 35.0 & $\begin{array}{c}108 . \\
0\end{array}$ \\
\hline $1.1 M d$ & 50.0 & & 600 & 62.0 & 51.0 & 28.6 & 62.0 & 75.9 & 43.0 & 52.8 & 60.0 & 94.0 & 50.0 & 75.9 & 64.0 & 108. \\
\hline
\end{tabular}

Note: $M$ in $\mathrm{kNm}$ and $\phi$ in $\mathrm{mrad}$.

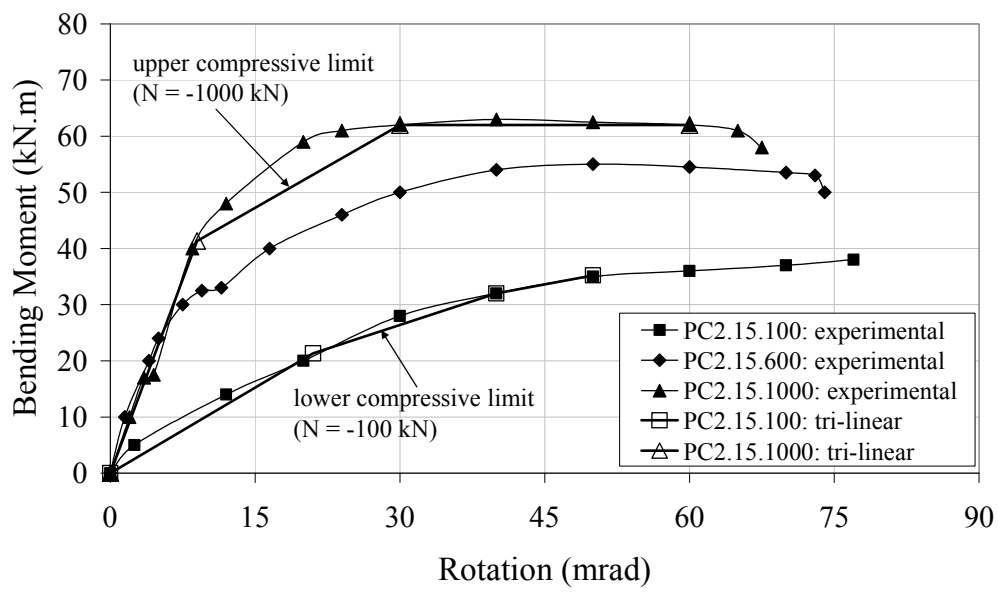

Figure 15. PC2.15 Experimental $M-\phi$ Curves and the Tri-linear Reference $M-\phi$ Curves

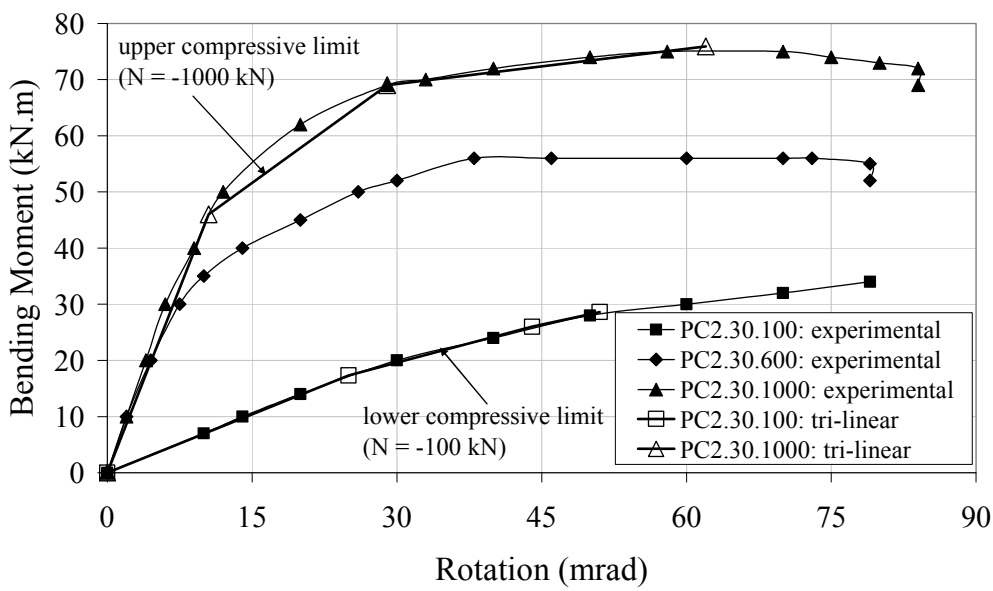

Figure 16. PC2.30 Experimental $M-\phi$ Curves and the Tri-linear Reference $M-\phi$ Curves 


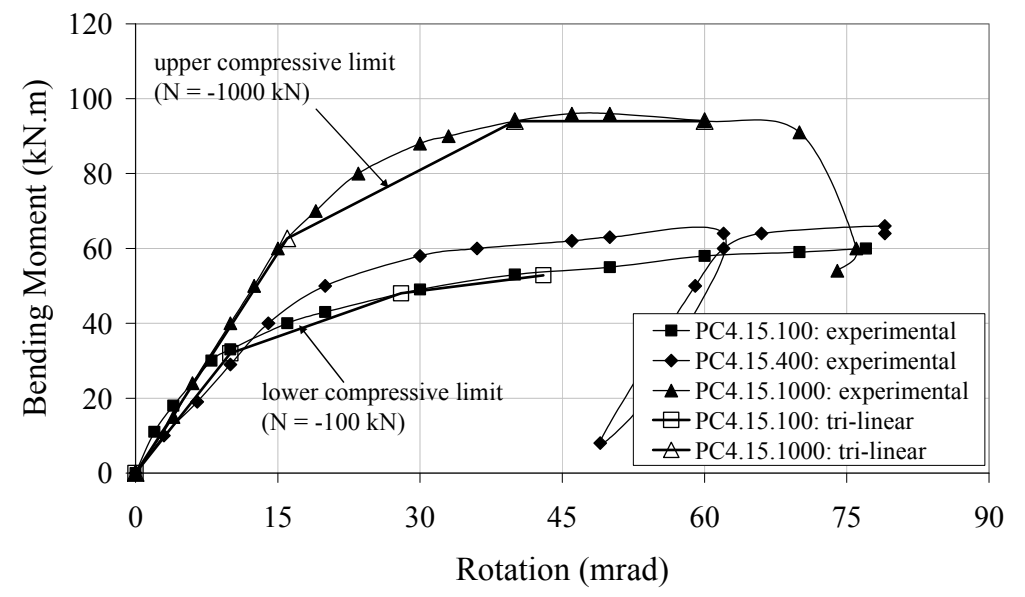

Figure 17. PC4.15 Experimental $M-\phi$ Curves and the Tri-linear Reference $M-\phi$ Curves

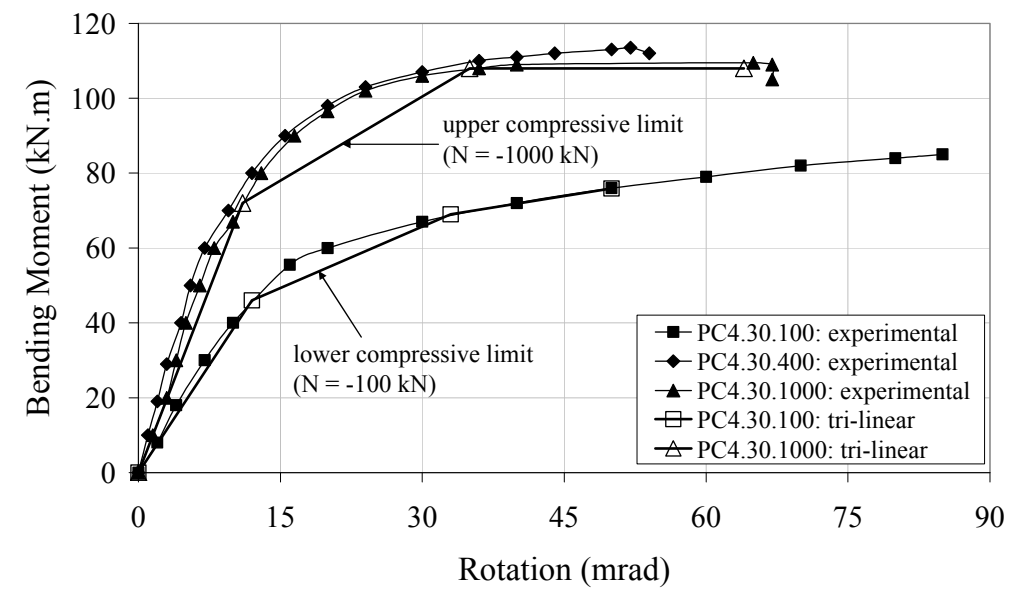

Figure 18. PC4.30 Experimental $M-\phi$ Curves and the Tri-linear Reference $M$ - $\phi$ Curves

Table 6 presents the results obtained by using the proposed method, with the aid of Eqs. 4 and 5, to predict four experimental $M-\phi$ curves: PC2.15.600; PC2.30.600; PC4.15.400 and PC4.30.400. Since there is no reference to experimental $M-\phi$ curve disregarding the axial force effect the experimental $M-\phi$ curves related to axial loads of $100 \mathrm{kN}$ are adopted for the base $M-\phi$ curves. This strategy implies that the axial force load $N$, associated with the reference $M-\phi$ curve, used in Eqs. 4 and 5, was decreased by $100 \mathrm{kN}$. Equation 7 demonstrates how to calculate point $2 / 3 M_{d}$, Table 6 , of the PC2.30.600 approximated $M-\phi$ curve. Finally, Figures 19 to 22 graphically show these results.

Table 6. Values Evaluated for Three Tri-linearly Approximated $M-\phi$ Curves

\begin{tabular}{cccccccccc}
\hline & \multicolumn{4}{c}{$\boldsymbol{P C 2}$} & \multicolumn{4}{c}{$\boldsymbol{P C 4}$} \\
$\Xi$ & $\mathbf{1 5 . 6 0 0}$ & $\mathbf{3 0 . 6 0 0}$ & $\mathbf{1 5 . 4 0 0}$ & \multicolumn{3}{c}{$\mathbf{3 0 . 4 0 0}$} \\
$\mathbf{Q}$ & $\boldsymbol{\phi}$ & $\boldsymbol{M}$ & $\boldsymbol{\phi}$ & $\boldsymbol{M}$ & $\boldsymbol{\phi}$ & $\boldsymbol{M}$ & $\boldsymbol{\phi}$ & $\boldsymbol{M}$ \\
\hline 0 & 0.0 & 0.0 & 0.0 & 0.0 & 0.0 & 0.0 & 0.0 & 0.0 \\
$2 / 3 M$ & 13.0 & 34.7 & 15.3 & 36.4 & 12.7 & 45.6 & 11.6 & 57.6 \\
$d$ & & & & & & & & \\
$M d$ & 33.3 & 52.0 & 34.0 & 54.7 & 33.3 & 68.4 & 33.9 & 86.3 \\
$1.1 M d$ & 56.7 & 53.1 & 58.3 & 60.1 & 50.6 & 71.1 & 56.2 & 90.2 \\
\hline
\end{tabular}

Note: $M$ in $\mathrm{kNm}$ and $\phi$ in mrad. $N_{i}$ is equal to $600 \mathrm{kN}$ for PC2 and $400 \mathrm{kN}$ for PC4. 
PC2.30.600: Point $=p=2 / 3 M_{d}$

$M_{p}=\left(M_{N, p}-M_{0, p}\right) \frac{N_{i}}{N}+M_{0, p}=(46.0-17.3) \frac{600.0}{1000.0-100.0}+17.3=36.4 \mathrm{kNm}$

$\phi_{p}=\left(\phi_{N, p}-\phi_{0, p}\right) \frac{N_{i}}{N}+\phi_{0, p}=(10.5-25.0) \frac{600.0}{1000.0-100.0}+25.0=15.3 \mathrm{mrad}$

$M_{N, p} ; \phi_{N, p}$ and $N \rightarrow$ Table $5: P C 2.30 .1000$

$M_{0, p}$ and $\phi_{0, p} \quad \rightarrow \quad$ Table $5: F C 2.30 .100$

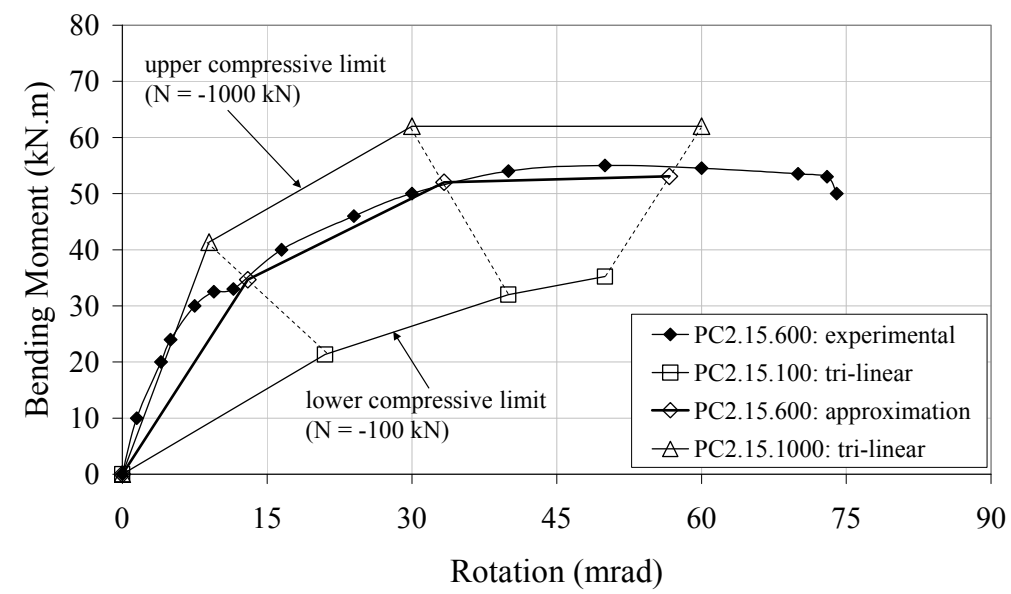

Figure 19. PC2.15.600 $M-\phi$ Curve Approximation

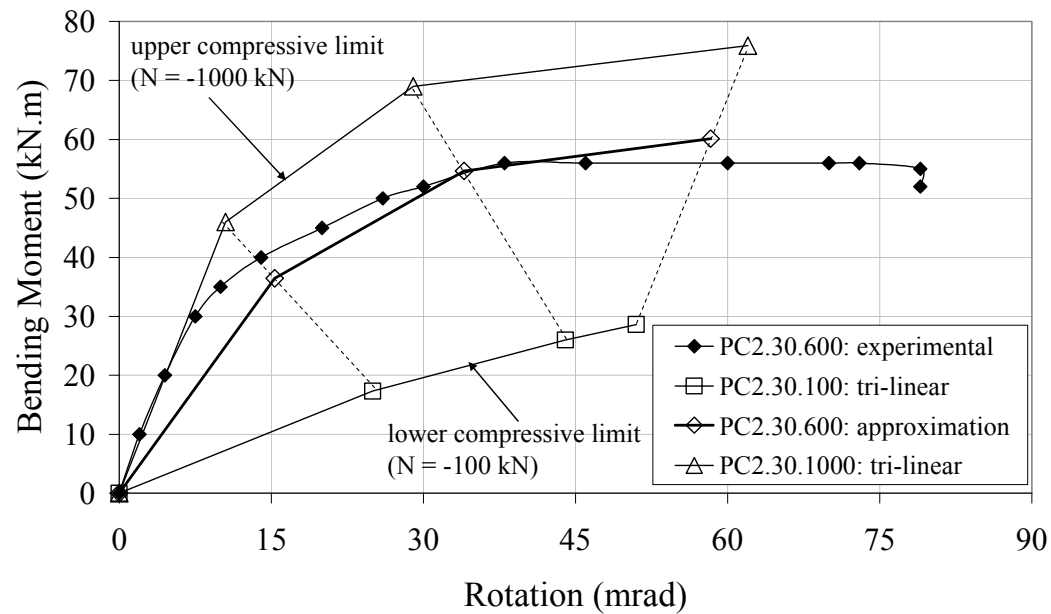

Figure 20. PC2.30.600 $M-\phi$ Curve Approximation 


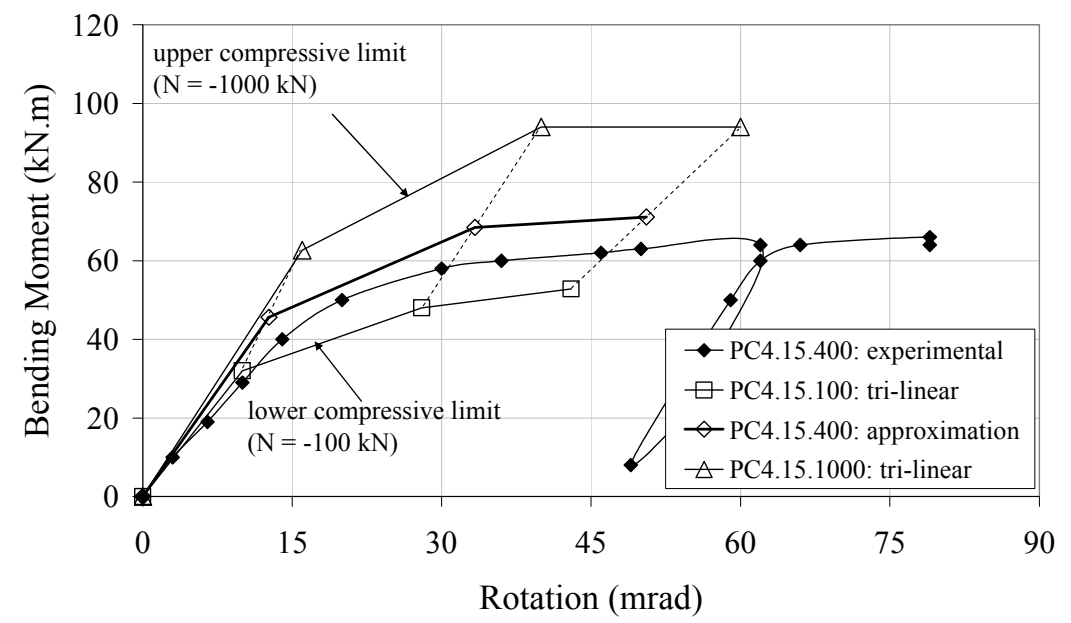

Figure 21. PC4.15.400 $M-\phi$ Curve Approximation

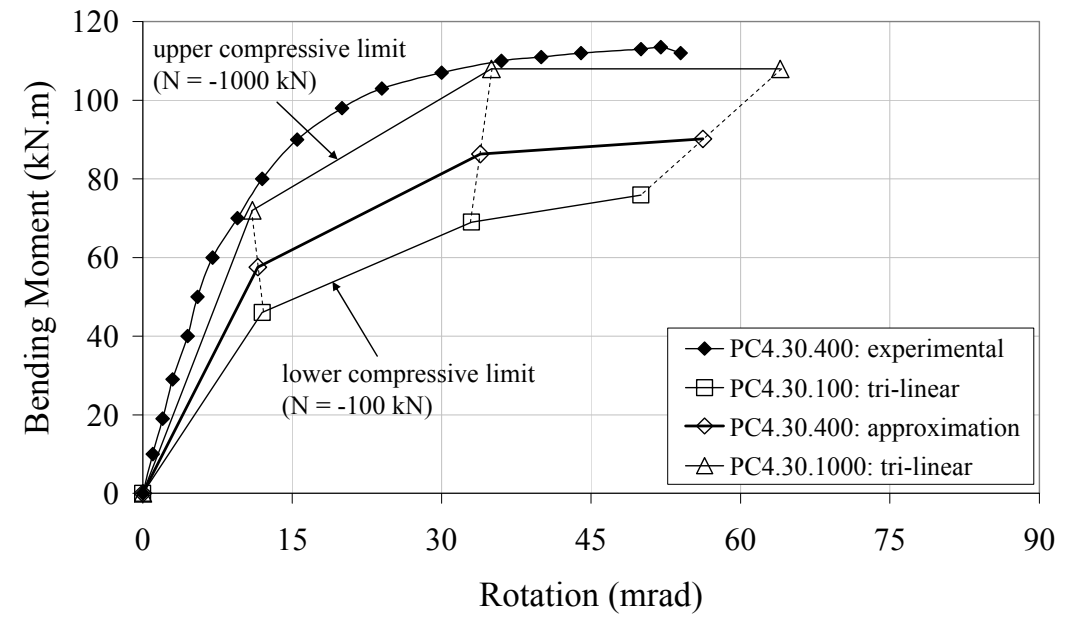

Figure 22. PC4.30.400 $M-\phi$ Curve Approximation

\section{RESULTS AND DISCUSSION}

Three flush endplate joint experimental $M-\phi$ curves, Simões da Silva et al. [13], were evaluated and are depicted in Figures 10-13. They were used to validate the proposed methodology presented in section 2.3 as well as to demonstrate its application.

Figure 10 illustrates an approximation for the FE8 $M-\phi$ curve that considers a tensile force equal to $10 \%$ of the beam's axial plastic resistance. This approximation was obtained from two tri-linear $M-\phi$ curves, disregarding and considering a tensile force of $20 \%$ of the beam's axial plastic resistance. This approximation was very close to the FE8 $M-\phi$ test curve, Table 7.

Figures 11 and 12, present approximations for FE3 and FE4 $M-\phi$ curves that respectively consider compressive forces of $4 \%$ and $8 \%$ of the beam's axial plastic resistance. These approximations were obtained from two tri-linear $M-\phi$ curves, disregarding and considering a compressive force of $20 \%$ of the beam's axial plastic resistance. The approximation for FE4 $M-\phi$ curve, Figure 12, was relatively close to the experimental curve, Table 7 . However, for FE3 $M-\phi$ curve, Figure 11, the obtained response was not as good, underestimating the joint flexural capacity by $11 \%$, Table 7 . This was due to the behaviour of this experimental curve when compared to the others. It is possible to observe in Figure 7 that there is an increase in the flush endplate joint moment capacity from FE1 $M-\phi$ curve $(N=0 \% N p l)$ to FE7 $M-\phi$ curve $(N=-20 \% N p l)$. However, within this range, 
with a $4 \%$ beam's compressive plastic resistance the flexural capacity is larger than the maximum moment obtained with the $8 \%$ test. Following this increasing tendency in the joint flexural capacity registered from FE1 $(\mathrm{N}=0 \% \mathrm{Npl})$ to FE7 $(\mathrm{N}=-20 \% \mathrm{Npl})$, the maximum moment obtained with FE4 $(N=-8 \% N p l)$ should be larger than FE3 $(N=-4 \% N p l)$. A possible reason for this perturbation in the experimental results might be related to problems with the FE3 experimental test such as measuring errors or assembly eccentricities.

In general, the predictions of the $M-\phi$ curves using the methodology proposed in section 2.3 provided accurate correlations with the test curves from Simões da Silva et al. [13] as can be seen in Table 7.

Table 7. Comparisons between the experimental and the proposed methodology in terms of initial stiffness and design moment capacity for flush endplate joints

\begin{tabular}{ccccccccc}
\hline \multirow{2}{*}{ Tests } & \multicolumn{3}{c}{ Initial Stiffness $(\boldsymbol{k N m} / \mathbf{r a d})$} & \multicolumn{4}{c}{ Design Moment $(\boldsymbol{k N m})$} \\
& Appr & Exp & Appr/Exp & \% & Appr & Exp & Appr/Exp & \% \\
\hline FE3 $(N=-4 \%$ Npl) & 8097 & 10132 & 0.80 & 20 & 74 & 83 & 0.89 & 11 \\
FE4 $(N=-8 \% ~ N p l)$ & 8147 & 10903 & 0.75 & 25 & 75 & 75 & 1.00 & 0 \\
FE8 $(N=+10 \%$ & 4568 & 5403 & 0.85 & 15 & 64 & 68 & 0.94 & 6 \\
\hline
\end{tabular}

Note: Negative percentage means overestimated value in \% whilst positive percentage indicates underestimated value in \%. Joint design moment was determined according to Eurocode 3 [3], through the intersection between two straight lines, one parallel to the initial stiffness and another parallel to the moment-rotation curve post-limit stiffness.

Regarding the tests performed by Guisse et al. [4], four baseplate experimental $M-\phi$ curves were evaluated and are presented in Figures 19 to 22. Figure 19 draws the prediction of PC2.15.600 M- $\phi$ curve for a compressive force of $600 \mathrm{kN}$, by using two reference $M-\phi$ curves: PC2.15.100 and PC2.15.1000. It is possible to note the very close approximation reached at the evaluated points: $2 / 3 M_{d}, M_{d}$ and $1.1 M_{d}$. On the other hand, the initial stiffness was rather erratic being estimated to be $44 \%$ (Table 8) smaller than the experimental one. This fact occurred because the point $2 / 3 M_{d}$, i.e. the first point of the approximated $M-\phi$ curves, is located above the onset point of physical separation of the plate and the concrete in the tensile zone. Therefore, the point $2 / 3 M_{d}$ was just able to capture the initial stiffness final change not considering the initial stiffness before the separation of the steel plate and the concrete base.

Figure 20 presents the PC2.30.600 $M$ - $\phi$ curve approximation for a compressive force of $600 \mathrm{kN}$, by utilising the reference $M-\phi$ curves: PC2.30.100 and PC2.30.1000. A reasonable approximation was obtained for this $M-\phi$ curve, however the initial stiffness was underestimated by $32 \%$ and the flexural capacity was slightly under predicted by $5 \%$, Table 8 .

Figure 21 demonstrates the PC4.15.400 $M-\phi$ curve prediction for a compressive force of $400 \mathrm{kN}$, by employing the base $M-\phi$ curves: PC4.15.100 and PC4.15.1000. A good correlation between the experimental tests and numerical results was obtained. Unlike the others results, the initial stiffness and the design bending moment were over predicted by $26 \%$ and $3 \%$, respectively.

Finally, Figure 22 presents the estimation of the PC4.30.400 $M-\phi$ curve for a compressive force of $400 \mathrm{kN}$, by having as basis PC4.30.100 and PC4.30.1000 M- $\phi$ curves. This case did not produce an accurate prediction of the $M-\phi$ curve, Table 8 . However, this fact may be justified due to the occurrence of the column end section yielding as well as column flange local plate buckling. In others words, the column capacity was reached before achieving the base plate joint flexural capacity. 
Table 8. Comparisons between the experimental and the proposed methodology in terms of initial stiffness and design moment capacity for baseplate joints

\begin{tabular}{ccccccccc}
\hline \multirow{2}{*}{ Tests } & \multicolumn{3}{c}{ Initial Stiffness $(\boldsymbol{k N m} / \mathbf{r a d})$} & \multicolumn{3}{c}{ Design Moment $(\boldsymbol{k N m})$} \\
& Appr & Exp & Appr/Ex & \% & Appr & Exp & Appr/Exp & \% \\
\hline$P C 2.15 .600$ & 2667 & 4800 & 0.56 & 44 & 52 & 54 & 0.96 & 4 \\
$P C 2.30 .600$ & 2377 & 3500 & 0.68 & 32 & 53 & 56 & 0.95 & 5 \\
$P C 4.15 .400$ & 3602 & 2857 & 1.26 & -26 & 65 & 63 & 1.03 & -3 \\
$P C 4.30 .400$ & 4981 & 9091 & 0.55 & 45 & 85 & 111 & 0.77 & 23 \\
\hline
\end{tabular}

Note: Negative percentage means overestimated value in \% whilst positive percentage indicates underestimated value in \%. Joint design moment was determined according to Eurocode 3 [3], through the intersection between two straight lines, one parallel to the initial stiffness and another parallel to the moment-rotation curve post-limit stiffness.

\section{CONCLUSIONS}

The main goal of this investigation was to present a consistent methodology to determine any moment versus rotation curve from experimental tests, including the axial versus bending moment interaction. This methodology can also be applied to results obtained analytically, empirically, mechanically, and numerically. Due to its simplicity and to the fact that its basis is $M-\phi$ curves that already consider the moment versus axial force interaction, it can be easily incorporated into a nonlinear semi-rigid joint finite element formulation. It is also important to observe that the use of the proposed methodology does not change the basic formulation of the non-linear joint finite element, only requiring a rotational stiffness update procedure.

This proposed method is a simple and accurate way of introducing semi-rigid joint experimental test data into structural analysis, through $M-\phi$ curves. Application and validation of the proposed methodology to obtain $M-\phi$ curves, for different axial force levels, were performed against experimental tests executed by Simões da Silva et al. [13] and Guisse et al. [4] on eight flush endplate and on twelve column base joints, respectively.

Finally, it may be suggested that an alternative, though accurate, method to determine $M-\phi$ curves for endplate and baseplate joints, considering the bending moment versus axial force interactions, can be made with a simple linear interpolation between two reference $M-\phi$ curves providing a straightforward procedure to obtain $M-\phi$ curves for any axial force level.

\section{ACKNOWLEGEMENTS}

The authors gratefully acknowledge the financial support provided by the Brazilian National and State Scientific and Technological Developing Agencies: CNPq, CAPES and FAPERJ. This arrangement financed the first author's period as a visiting scholar at Imperial College London.

\section{REFERENCES}

[1] Cerfontaine, F., "Etude de l'interaction Entre Moment de Flexion et Effort Normal Dans Les Assemblages Boulonnés", Doctor en Sciences Appliquées - Université de Liege, Faculté des Sciences Appliquées, 2003. (in French). 
[2] Del Savio, A.A., Andrade, S.A. de, Vellasco, P.C.G.S., Martha, L.F. and Lima, L.R.O. de., "Semi-Rigid Portal Frame Finite Element Modelling Including the Axial Versus Bending Moment Interaction in the Structural Joints", Proceedings of International Colloquia on Stability and Ductility of Steel Structures - SDSS'06, Lisboa, 2006, Vol. 1, pp.1-8.

[3] European Committee for Standardisation, Eurocode 3: Design of Steel Structures - Part 1.8: Design of Joints, Brussels, May 2005.

[4] Guisse, S., Vandegans, D. and Jaspart, J.-P., "Application of the Component Method to Column Bases - Experimentation and Development of a Mechanical Model for Characterization", Report No. MT 195, Liege: Research Centre of the Belgian Metalworking Industry, 1996.

[5] Jaspart J.-P., Braham, M. and Cerfontaine, F., "Strength of Joints Subjected to Combined Action of Bending Moments and Axial Forces", Proceedings of the First European Conference on Steel Structures, Eurosteel, 1999, pp.465-468.

[6] Li, T.Q., Choo, B.S. and Nethercot, D.A., "Connection Element Method for the Analysis of Semi-Rigid Frames", Journal Constructional Steel Research, 1995, Vol. 32, pp.143-171.

[7] Lima, L.R.O. de., "Behaviour of Endplate Beam-to-Column Joints under Bending and Axial Force". Ph.D. Thesis. PUC-Rio, Pontifical Catholic University, Civil Eng. Dept., Rio de Janeiro, Brazil, 2003. (in Portuguese)

[8] Lima, L.R.O. de, Simoes da Silva, L., Vellasco, P.C.G.S. and Andrade, S.A. de., "Experimental Evaluation of Extended End-Plate Beam-to-Column Joints Subjected to Bending and Axial Force", Engineering Structures, 2004, Vol. 26, pp.1333-1347.

[9] Madas, J.P., "Advanced Modelling of Composite Frames Subjected to Earthquake Loading". PhD Thesis, Imperial College Science, Technology and Medicine, University of London, 1993.

[10] Nethercot, D.A. and Zandonini, R., "Methods of Prediction of Joint Behaviour: Beam-to-Column Connections", Structural Connections: Stability and Strength, Elsevier Applied Science, London and New York, Chapter 2, pp.23-62, 1989.

[11] Ramli-Sulong, N.H., "Behaviour of Steel Connections under Fire Conditions". PhD Thesis, Imperial College London, University of London, 2005.

[12] Simões da Silva, L. and Coelho, A.M.G., "An Analytical Evaluation of the Response of Steel Joints under Bending and Axial Force", Computers and Structures, 2001, Vol. 79, pp. 873-881.

[13] Simões da Silva, L., Lima, L.R.O. de, Vellasco, P.C.G.S. and Andrade, S.A. de., "Behaviour of Flush End-Plate Beam-to-Column Joints under Bending and Axial Force", Steel and Composite Structures, 2004, Vol. 4, No. 2, pp. 77-94.

[14] Sokol, Z., Wald, F., Delabre, V., Muzeau, J.-P. and Svarc, M., "Design of Endplate Joints Subject to Moment and Normal Force", Proceedings of Third European Conference on Steel Structures - Eurosteel 2002, Coimbra, Comm Press, 2002, pp. 1219-1228.

[15] Urbonas, K. and Daniunas, A., "Behaviour of Semi-Rigid Steel Beam-to-Beam Joints under Bending and Axial Forces", Journal of Constructional Steel Research, 2006, Vol. 62, pp. 1244-1249.

[16] Vlassis, A.G., Izzuddin, B.A., Elghazouli, A.Y. and Nethercot, D.A., "Design Oriented Approach for Progressive Collapse Assessment of Steel Framed Buildings", Structural Engineering International (Report), SEI Editorial Board, 2006, pp. 129-136.

[17] Wald, F. and Svarc, M., "Experimental with Endplate Joints Subject to Moment and Normal Force. Contribution to Experimental Investigation of Engineering Materials and Structures", CTU Report n: 2-3, Prague, 2001, pp. 1-13.

[18] Wales, M.W. and Rossow, E.C., "Coupled Moment-Axial Force Behaviour in Bolted Joints”, Journal of Structural Engineering, ASCE, 1983, Vol. 109, No. 5, pp. 1250-1266. 